rural communities living within the vicinity of roads. Development aid meant for road building takes no account of road safety, and there seems to be neglect of the fact that thousands will die and many more thousands will be injured while using roads in Africa and other parts of the world.

Under-reporting of road traffic injury is a major problem in Africa and virtually all countries of the world. ${ }^{110}$ About 200000 people died on African roads in 2002, ${ }^{1}$ and probably many more but we do not have an accurate picture because of the problem of under-reporting. A large proportion of those affected are pedestrians and passengers on public transport. ${ }^{111}{ }^{12}$ Institutional and economic factors that lead to the problem of under-reporting need to be addressed. Governments and development partners need to take practical steps to improve data collection, analysis, and sharing among different agencies.

The lesson we have learnt from our practical experience in supervising implementation of road safety projects in low income and middle income countries, including Africa, is that road safety has a socioeconomic and political context. Real progress can be made if development agencies and governments deal realistically with this context. Road safety is no accident: it is the result of deliberate efforts by many sectors of society, both governmental and nongovernmental, that have acknowledged it to be an important and valuable public good and have developed policies and programmes to support and maintain it. Development agencies, governments and non-governmental organizations need to allocate financial and human resources to address the road safety problem; identify and support a lead agency with authority and responsibility to guide national road safety efforts; prepare or revisit national road safety strategies and plans of action; implement specific actions such as enforcement of road safety regulations on speed and alcohol; and improve data collection on road traffic crashes in Africa. The time for action is now.

Meleckidzedeck Khayesi technical officer

(khayesim@who.int)

Margie Peden coordinator, unintentional injury prevention

Department of Injuries and Violence Prevention, World Health Organization, 20 Avenue Appia, CH-1211 Geneva, Switzerland

Competing interests: None declared.

1 Peden M, Scurfield R, Sleet D, Mohan D, Hyder AH, Jarawan E, et al. World report on road traffic injury prevention. Geneva: World Health Organization, 2004. www.who.int/world-health-day/2004/infomaterials world_report/en/ (accessed 22 Sep 2005).

2 United Nations. The road from Johannesburg: what was achieved and the way forward. New York: United Nations, Department of Economic and Social Affairs, 2003.

3 Darkoh MBK. Sub-Saharan Africa in crisis and the need for a new domestic order. In: Yeung Y, ed. Global change and the commonwealth. Hong Kong: Hong Kong Institute of Asia Pacific Studies, Chinese University of Hong Kong, 1996:45-65.

4 World Bank. Sub-Saharan Africa:from crisis to sustainable growth. Washington, DC: World Bank, 1989.

World Bank. African development indicators 2004. Washington, DC: World Bank, 2004.

Sachs J. The end of poverty: economic possibilities for our time. New York: Penguin Press: 2005.

7 Bishai D, Hyder AA, Ghaffar A, Morrow RH, Kobusingye O. Rates of public investment for road safety in developing countries: case studies of public investment for road safety in developing countries:

8 Alila P, Khayesi M, Odhiambo W, Pedersen PO. Development of African freight transport-the case of Kenya. Copenhagen: Danish Institute for International Studies, 2005. (Working paper No 2005/6.)

9 Howe J. The headloading and footpath economy-walking in sub-Saharan Africa. World Transport Policy and Practice 2001;7(4):8-12.

10 Roberts I. Death on the road to international development. BMJ 2005;330:972

1 Nantulya VM, Muli-Musiime F. Kenva: uncovering the social determinants of road traffic accidents. In: Evans T, Whitehead D, Diderichsen $\mathrm{F}$, Bhuiya A, Wirth M, eds. Challenging inequities: from ethics to action. New

12 Odero W, Garner P, Zwi A. Road traffic injuries in developing countries: a comprehensive review of epidemiological studies. Trop Med Intl Health 1997:2:445-60.

\title{
Tackling cardiovascular disease in Africa
}

\section{Will need much more than just imported measures from more developed countries}

I $\mathrm{n}$ the past four decades Africa has witnessed increasing urbanisation and changing lifestyles, factors which have, in turn, raised the incidence of non-communicable chronic diseases, especially cardiovascular disease. At the same time social disintegration and inequality, compounded by the dwindling economy in many countries in sub-Saharan Africa, have seriously hindered the response to these non-communicable diseases. Moreover, communicable diseases are still rife, using up health resources, and actions to deal with communicable diseases have often been based on data from smaller studies, usually hospital based. The situation is cause for concern.

Cardiovascular disease has reached near epidemic proportions in Africa. According to the World Health Report 2002, cardiovascular disease accounted for 9.2\% of total deaths in the African region in 2001, and hypertension, stroke, cardiomyopathies and rheumatic heart disease were the most prevalent causes. ${ }^{1}$ such as myocardial infarction and angina are relatively uncommon in most parts of Africa, heart failure is often seen. The World Health Organization has reported that the number of disability adjusted life years lost to cardiovascular disease in sub-Saharan Africa rose from 5.3 million for men and 6.3 million for women in 1990 to 6.5 million and 6.9 million in 2000 , and could rise to 8.1 million and 7.9 million in 2010. Cardiovascular disease has higher mortality in developing countries than in developed ones, ${ }^{2}$ and affects younger people and women disproportionately.

Hypertension remains the most threatening risk factor, with national prevalences ranging between 15\% and $30 \%$ in adults. Extrapolations from studies in Nigeria and elsewhere indicate that $5 \%$ of deaths could be due to hypertension and that the reduction in attributable risk associated with treatment could be $2 \%$, over 10 times higher than in the United States.. The usual risk factors of obesity, smoking, heavy drinking, physical inactivity, and inappropriate diet are all 
relevant in Africa. So must be adverse intrauterine environment, given that antenatal care is poor or absent in most parts of the continent. People often have multiple risk factors, as shown in a recent publication from South Africa which reported that $32.1 \%$ of men and $18.9 \%$ of women over 30 had a $20 \%$ or higher likelihood of developing cardiovascular disease in the next 10 years. ${ }^{4}$

Barriers to planning and providing care for people with cardiovascular disease compound the problem. For example, inadequate classification of deaths from cardiovascular disease in South Africa and of differences in patterns of risk and disease among ethnic groups hampered effective planning. ${ }^{5}$ Providers of primary and secondary health care in Nigeria reported barriers to managing cardiovascular risk which included inadequate financing, low competence among health workers, and poor laboratory support. ${ }^{6}$ And another study in Gambia found that poor recording of demographic data hindered the smooth execution of a project for people with cardiovascular disease. ${ }^{7}$ Furthermore, and unsurprisingly, Africa has the lowest output in the world of cardiovascular research. $^{8}$

There is hope though, and some attention has finally been focused on cardiovascular disease in Africa. The International Forum for Hypertension Control and Prevention in Africa published clinical management guidelines for the whole continent in $2003 .^{9}$ National initiatives to identify risk factors and set guidelines are now under way. Some countries have carried out national epidemiological surveys, a few have begun to continually monitor and assess their programmes, and some countries, South Africa and Nigeria among them, have their own guidelines for managing hypertension.

Such national and local strategies are essential, not least because measures imported wholesale from developed countries may not always be directly applicable locally. Health authorities and doctors know what they need to do to tackle cardiovascular disease. But difficulties such as underfunding, poor infrastructure, inadequate access to cheap generic drugs and fixed dose combinations, and lack of public recognition and acceptance of the importance of cardiovascular disease will continue to hinder the effective implementation of both population based health programmes and those aimed at people at high risk. The continent's people need education on healthier (but, perhaps in some African societies, culturally undesirable) lifestyles such as weight reduction, smoking cessation, and greater physical activity.

\section{S Kadiri consultant physician}

Department of Medicine, University College Hospital, Ibadan, Nigeria (skadiri@skannet.com)

Competing interests: None declared.

1 World Health Organization. World health report 2002. Reducing risks, promoting healthy life. Geneva: WHO, 2002, www.who.int/whr/2002/en/ promoting healthy life. Geneva: WHO,

2 Reddy KS, Yusuf S. Emerging epidemic of cardiovascular disease in developing countries. Circulation 1998;97:596-601.

3 Cooper RS, Rotimi CN, Kaufman JS, Muna WFT, Mensah GA. Hypertension treatment and control in sub-Saharan Africa: the epidemiologic basis for policy. BMJ 1998; 16:614-7.

4 Alberts M, Urdal P, Steyn K, Stensvold I, Tverdal A, Nel JH et al. Prevalence of cardiovascular diseases and associated risk factors in a rural black population of South Africa. Eur I Cardiovasc Prev Rehabil 12.347-354.

5 Bradshaw D. What do we know about the burden of cardiovascular disease in South Africa? Cardiovasc J South Afr 2005;16:140-1.

6 Mendis S, Abegunde D, Oladapo O, Celleti F, Nordet P. Barriers to management of cardiovascular risk in a low-resource setting using hypertension as an entry point. $J$ Hypertens 2004;22:59-64.

Kobal SL, Czer LSC, Czer P, Feldsher Z, Hamilton R, Siegel RJ. Making an impossible mission possible. Chest 2004;125:293-6.

8 Rosmarakis ES, Vergidis PI, Soteriades ES, Paraschakis K, Papastamataki $\mathrm{PA}$, Falagas ME Estimates of global production in cardiovascular diseases research Int J Cardiol 2005; 100:443-9.

9 Lemogoum D, Seedat YK, Mabadeje AF, Mendis S, Bovet P, Onwubere B, et al; International Forum for Hypertension control and prevention in Africa. Recommendations for prevention, diagnosis and management of hypertension and cardiovascular risk factors in sub-Saharan Africa. $J$ Hypertens 2003;21:1993-2000.

\section{BMA and BMJ Information Fund}

The British Medical Association and the $B M J$ have established a small fund to enable us to respond to requests for health information from organisations in developing countries and other areas of need.

The fund does not grant money; rather, it provides educational materials such as books, journals, CD Roms, and DVDs. In the case of organisations with internet facilities, we may be able to provide access to online journals. We are unable to accept applications from individuals but are pleased to consider applications from, or on behalf of, medical schools, medical libraries, healthcare institutions and related organisations, including non-governmental organisations.

The closing date for 2005 applications is Friday 11 November 2005.

For more information and to make an application go to www.bma.org.uk/infofund. 